\title{
The Role of Spinal Cord Vanilloid (TRPV1) Receptors in Pain Modulation
}

\section{D. ŠPICAROVÁ, J. PALEČEK}

Department of Functional Morphology, Institute of Physiology, Academy of Sciences of the Czech Republic, v.v.i, Prague, Czech Republic

Received February 15, 2008

Accepted April 16, 2008

On-line May 13, 2008

\section{Summary}

Transient receptor potential vanilloid 1 (TRPV1) receptor is a nonselective cation channel activated by capsaicin, a pungent substance from chili peppers. It is considered to act as an integrator of various physical and chemical nociceptive stimuli, as it can be gated by noxious heat $\left(>43^{\circ} \mathrm{C}\right)$, low $\mathrm{pH}$ (protons) and also by recently described endogenous lipids. The structure and function of TRPV1 receptors was vigorously studied, especially since its cloning in 1997. However, most of the research was pointed towards the role of TRPV1 receptors in the peripheral tissues. Mounting evidence now suggests that TRPV1 receptors on the central branches of dorsal root ganglion neurons in the spinal cord may play an important role in modulation of pain and nociceptive transmission. The aim of this short review was to summarize the knowledge about TRPV1 receptors in the spinal cord dorsal horn, preferentially from morphological and electrophysiological studies on spinal cord slices and from in vivo experiments.
\end{abstract}

\section{Key words}

Hyperalgesia • Capsaicin • TRPV1 • Spinal cord

\section{Corresponding author}

J. Paleček M.D., Ph.D., Department of Functional Morphology, Institute of Physiology ASCR, Vídeňská 1083, 14220 Prague 4, Czech Republic, Fax: (+420) 24106 2488. E-mail: palecek@biomed.cas.cz

\section{Introduction}

Capsaicin, the pungent substance from chili peppers, was repeatedly used in pain research for its ability to induce both hyperalgesia and analgesia, depending on the concentration and route of application (Jancso et al. 1987, Willis 2001, Knotkova et al. 2008). It was in 1997 (Caterina et al. 1997) that the specific receptor activated by capsaicin (transient receptor potential vanilloid 1 - TRPV1) was cloned and characterized. Since then, numerous studies were published characterizing the biophysical and physiological properties, while its possible therapeutic use for pain treatment was pursued (Numazaki et al. 2004, Szallasi et al. 2007, Vennekens et al. 2008). The aim of this short review was to summarize the knowledge about TRPV1 receptors in the spinal cord dorsal horn, preferentially from morphological and electrophysiological studies on spinal cord slices and from in vivo experiments.

\section{Vanilloid TRPV1 receptors}

The TRPV1 receptors belong to a large family of TRP channels (Venkatachalam and Montell 2007). TRPV1 receptor formerly known as the vanilloid receptor (VR1) is the founding member of the TRPV subfamily and belongs to the group of six thermosensitive channels in mammals (TRPV2, TRPV3, TRPV4, TRPM8 and TRPA1). TRPV1 receptors are considered to be integrators of noxious chemical and physical stimuli that can be activated by capsaicin, heat, low $\mathrm{pH}$ and also by recently described endogenous lipids derived from dopamine (Tominaga et al. 1998, Numazaki et al. 2004, Vennekens et al. 2008). There are numerous studies published that confirm the crucial role 
of these receptors for transduction and modulation of acute and chronic pain. Based on these studies a substantial potential for treatment of different acute and chronic pain disorders and other diseases is recently emerging (Szallasi et al. 2007).

TRPV1 receptors are specifically activated by capsaicin, a substance that was used frequently in the pain research to activate nociceptors in the past, when the mechanisms of its action were not known. It was recognized that its application can have both analgesic and algesic effects based on the concentration used and the form of administration. Systemic high concentration capsaicin administration in neonatal rats is neurotoxic and leads to selective degeneration of capsaicin sensitive primary neurons (Jancso et al. 1977, 1987, Nagy et al. 1983). High concentration intradermal injection of capsaicin was also shown to induce degeneration of epidermal nerve fibers in humans (Simone et al. 1998) and to reduce signs of postoperative pain in rats (Pospisilová and Palecek 2006). Intradermal application of low concentration capsaicin leads to acute pain, followed by mechanical hyperalgesia in humans (Simone et al. 1989) and to sensitization of spinothalamic tract neurons (Simone et al. 1991).

Breakthrough in the TRPV1 receptor research came with the cloning of cDNA encoding the receptor by Caterina et al. in 1997 and construction of TRPV1 -/knockout mice three years later. Mice lacking TRPV1 receptors had normal responses to noxious mechanical stimuli, but detection of noxious heat was impaired, inflammatory thermal hypersensitivity was attenuated, pain behavior induced by capsaicin application was abolished (Caterina et al. 2000) and the development of carrageenan-mediated thermal hyperalgesia was completely absent (Davis et al. 2000).

The majority of the research was oriented to study the function of TRPV1 receptors in the peripheral nervous system and to define the biophysical properties in different expression systems using cell cultures (Cortright and Szallasi 2004, Szallasi et al. 2007, Vennekens et al. 2008). It was well established that peripheral TRPV1 receptors, acting as integrators of nociceptive stimuli, can be sensitized or activated by inflammatory mediators such as bradykinin, prostaglandins or protons (Cortright and Szallasi 2004). The number of peripheral receptors is also increased by transport of TRPV1 to the peripheral terminals of small diameter sensory neurons by NGF action under inflammatory conditions (Ji et al. 2002).
In contrast, the role of central TRPV1 receptors in the spinal cord dorsal horn was not studied extensively and the function of these receptors in pain transmission and modulation is not fully understood. The activation of spinal TRPV1 receptors is not as straightforward as in the periphery, where temperature increase, low $\mathrm{pH}$ or release of different molecules due to tissue damage can gate or sensitize the receptor. A great effort was thus employed to detect possible endogenous agonists of central TRPV1 receptors (Starowicz et al. 2007). Anandamide ( $N$-arachidonoylethanolamine), an endogenous ligand of cannabinoid receptors was one of the first substances suggested to be an endogenous ligand of TRPV1 receptors (Zygmunt et al. 1999). Also several products of lipoxygenases (12- and 15-HPETE, 5- and 15-HETE) were found to directly activate TRPV1 receptors in isolated membrane patches of sensory neurons (Hwang et al. 2000). Endogenous agonists of TRPV1 were found between unsaturated $\mathrm{N}$ acyldopamines isolated from bovine striatal extract. $\mathrm{N}$ arachidonoyldopamine (NADA) potently activated native TRPV1 in neurons from rat DRG thereby inducing release of substance $\mathrm{P}$ and calcitonin generelated peptide (CGRP) from spinal cord slices (Huang et al. 2002). $N$-oleoyldopamine (OLDA) induced calcium influx in TRPV1-transfected HEK cells and dose-dependent thermal hyperalgesia when injected subcutaneously in plantar surface of the paw (Chu et al. 2003). Direct interaction of omega-3 polyunsaturated fatty acids with TRPV1 was demonstrated by Matta et al. (2007). For example docosahexaenoic acid can act as an agonist, whereas eicosapentaenoic and linolenic acid exhibit inhibitory effect on the TRPV1 receptors.

\section{Spinal cord TRPV1 receptors distribution}

High density of TRPV1 receptors was detected and visualized in the superficial dorsal horn of the spinal cord using radiolabeled resiniferatoxin $\left(\left[{ }^{3} \mathrm{H}\right] \mathrm{RTX}\right)$, an ultra potent analog of capsaicin, in the rat, pig and man (Szallasi et al. 1994). Staining for TRPV1 receptors was absent or highly reduced following administration of high, neurotoxic doses of capsaicin and ipsilaterally after unilateral dorsal rhizotomy, suggesting that the majority of the TRPV1 receptors in the spinal cord are present on the central branches of dorsal root ganglion (DRG) sensory neurons (Szallasi et al. 1994, Guo et al. 1999, Valtschanoff et al. 2001). DRG neurons express TRPV1 not only on both central and peripheral terminals, but 
also on the cell bodies (Acs et al. 1994). The expression of TRPV1 receptors in DRG neurons is restricted to small and medium sized cells with $\mathrm{C}$ and $\mathrm{A}-\delta$ axons, corresponding to nociceptors. It was demonstrated by in situ hybridization for TRPV1 mRNA (Caterina et al. 1997) and by TRPV1-immunoreactivity (Guo et al. 1999).

Capsaicin sensitive primary afferent fibers terminate predominantly in lamina I and II of the superficial dorsal horn, the inner part of lamina II ( $\left.\mathrm{II}_{\mathrm{i}}\right)$ receiving substantial input compared to outer part $\left(\mathrm{II}_{\mathrm{o}}\right)$ (Guo et al. 1999, Valtschanoff et al. 2001). Notable TRPV1 expression was also found along the lateral collateral path, where the majority of visceral afferents terminate and sporadic TRPV1-immunostaining was detected in laminae III-V (Hwang and Valtschanoff 2003). Study by Valtschanoff et al. (2001) demonstrated also occurrence of postsynaptic TRPV1 in the superficial dorsal horn in rat. They observed patchy TRPV1 immunostaining in cell bodies in lamina II, which was dependent on presynaptic input, as it was lost after dorsal rhizotomy. Spinal neurons expressing TRPV1 receptors were confirmed also in other studies, where it was shown that some of them were also immunopositive for NK1 receptor (Doly et al. 2004a,b).

The density of TRPV1 receptors changes longitudinally in the spinal cord as was shown by $\left[{ }^{3} \mathrm{H}\right] \mathrm{RTX}$ autoradiography. The receptor labeling was comparable in the cervical and thoracic segments (approximately $70 \mathrm{fmol} / \mathrm{mg}$ protein) but it was twice as high in the lumbar segment, while membranes obtained from all spinal cord segments showed similar affinities for RTX (Szallasi et al. 1995). Immunofluorescent and confocal microscopy showed that the density of TRPV1positive fibers and buttons in the dorsal horn increases progressively from lumbar segments L4 to L6 (Hwang and Valtschanoff 2003). This study also suggested that TRPV1 receptors are preferentially expressed by visceral afferents.

The TRPV1 receptors density and their localization in the spinal cord are changing during development. Neonatal rats at postnatal day 2 (P2) have three-fold higher expression of TRPV1 than have adult rats (Acs et al. 1994). The shift of appearance of TRPV1 protein in the terminals of sensory neurons over postnatal period was demonstrated by Guo et al. (2001). As early as embryonic day (E) 16 and P2, TRPV1 immunoreactivity was only observed in lamina $I$ and hardly visible in lamina II. However, at P10 the expression zone became wider and appeared to diffuse into lamina II. This pattern was enhanced at P20, when TRPV1 immunoreactivity was further developed and more prominent in lamina II. By P30 TRPV1 immunoreactivity appeared as two distinctive zones notably in lamina $\mathrm{I}$ and $\mathrm{II}_{\mathrm{i}}$ corresponding to the pattern present in adult animals.

Recently, TRPV1 receptors were observed not only in neurons but also in glial cells in the rat dorsal horn of the spinal cord. Using immunocytochemistry at the ultrastructural level, TRPV1 receptors were detected in astrocytes by double labeling with glial fibrillary acid protein in both laminae I and II, where TRPV1 positive astrocytes corresponded to $7 \%$ of the total TRPV1 labeling in this area (Doly et al. 2004b).

\section{Colocalization of TRPV1 positive fibers with peptides in the spinal cord}

Capsaicin administration on the spinal cord slice elicits simultaneous release of neuropeptides substance $P$ (SP) and calcitonin gene-related peptide (CGRP) in the dorsal horn (Saria et al. 1986). As well, intrathecal capsaicin application results in depletion of SP from primary sensory neurons and increased thresholds for thermal and chemical stimuli (Yaksh et al. 1979). It was shown that about $30 \%$ of TRPV1 positive DRG neurons co-express also SP, while about $75 \%$ of SP positive neurons are also TRPV1 positive and this remains quite constant during development (Guo et al. 2001). In contrast, the extent of colocalization of TRPV1 and SP immunoreactivity in the superficial dorsal horn was much less than anticipated, given their coexistence in DRG cell bodies (Guo et al. 1999, Valtshanoff et al. 2001). While the colocalization of TRPV1 with SP in lamina $I$ and along the lateral collateral path was unfrequented at L4, it was much more robust at L6 level, which is consistent with a higher degree of colocalization of TRPV1 and SP in visceral than in cutaneous afferents (Hwang and Valtschanoff, 2003). There is significant coexpression of TRPV1 with pain related $\mathrm{P}_{2} \mathrm{X}_{3}$ purinoceptor and with glycoprotein that binds the lectin IB4 in lamina $\mathrm{II}_{\mathrm{i}}$ (Guo et al. 1999).

It was shown before that about $80 \%$ of lamina I projection neurons express receptor for SP (neurokinin receptor NK1) (Todd 2002) and that these neurons play a major role in thermal hyperalgesia (Mantyh et al. 1997). Immunohistochemical study showed that there are direct contacts of TRPV1 containing afferents with NK1- 
positive dorsal horn neurons in lamina I. By retrograde tracing, it was also suggested that most of these synapses represented a monosynaptic pathway from periphery to the lateral parabrachial nucleus (Hwang et al. 2003). It was confirmed that the TRPV1 positive primary afferents are glutamatergic and contact spinal neurons that express main classes of ionotropic glutamate receptors (Hwang et al. 2004). The multiple immunofluorescent staining for TRPV1, AMPA and NMDA receptors also showed that a larger fraction of NK1/NMDA receptors positive sites were contacted by TRPV1 positive buttons, than those expressing TRPV1/AMPA receptors (Hwang et al. 2004).

\section{TRPV1 impact on synaptic transmission in the spinal cord dorsal horn}

Evidence of capsaicin evoked glutamate release from primary afferent fibers in rat was given by Ueda et al. (1994). The release of glutamate was measured using a fluorometric on-line monitoring system connected to an in vitro superfusion system. Administration of capsaicin produced an increased outflow of glutamate and depletion of SP from dorsal horn slices. The capsaicin induced glutamate and SP release was concentration dependent in the range of 0.1-3 $\mu \mathrm{M}$ and 1$10 \mu \mathrm{M}$, respectively. Dorsal rhizotomy counteracted capsaicin induced increase of glutamate release from the DH of the spinal cord. Furthermore, it was shown that SP and CGRP, which are depleted by capsaicin, enhanced release of glutamate and aspartate from the rat spinal dorsal horn slice (Kangrga and Randic 1990). Imunohistochemistry revealed depletion of not only SP but also cholecystokinin (CCK) following intrathecal capsaicin administration in concentration eliciting analgesia in rat (Micevych et al. 1983). In contrast, depletion of CCK was not confirmed by radioimmunoassay and in vivo superfusion of the rat spinal cord, where capsaicin elicited release of SP but not CCK (Jhamandas et al. 1984).

The effect of increased glutamate release on excitatory synaptic transmission in superficial dorsal horn following capsaicin application was shown also by electrophysiological methods. Capsaicin $(2 \mu \mathrm{M})$ administration evoked dramatic increase of spontaneous and miniature excitatory postsynaptic current (mEPSC) frequency in slices from adult rats. This activity was prevented by pretreatment with capsazepine, a competitive TRPV1 antagonist, and blocked by CNQX, a non-NMDA glutamate receptor antagonist (Yang et al. 1998). Capsaicin elicited increase in mEPSC frequency was demonstrated already from $\mathrm{P} 0$ with dramatic enhancement of the effect between P6 and P10. However, capsazepine failed to block the increase of mEPSC frequency elicited by the same concentration of capsaicin $(2 \mu \mathrm{M})$ in rat pups (P8-P11), while it was completely abolished by pretreatment with ruthenium red, a non-competitive TRPV1 antagonist (Baccei et al. 2003). Differential role of TRPV1 receptors on central branches of $\mathrm{C}$ and $\mathrm{A}-\delta$ primary afferent fibers was suggested by experiments, in which C-fibers evoked EPSCs were inhibited by capsaicin administration in approximately $80 \%$ of substantia gelatinosa (SG) neurons, while $\mathrm{A}-\delta$ fibers elicited excitatory transmission was unaffected in adult rats (Yang et al. 1999). Capsaicin abolished dorsal horn neurons EPSCs evoked by electrical stimulation of attached dorsal root in pups (P7-P10), but facilitation of spontaneous glutamate release by capsaicin was sufficient to produce bursts of action potentials in superficial DH neurons in early postnatal age (P1-P5) (Baccei et al. 2003).

Originally it was assumed that inhibitory synaptic transmission in superficial DH of the spinal cord is not affected by TRPV1 receptors. GABAergic and glycinergic spontaneous inhibitory postsynaptic currents (IPSCs), and also A- $\delta$ fibers evoked IPSCs were unaffected by capsaicin administration in adult rats (Yang et al. 1998, Yang et al. 1999). However, based on immunohistochemistry it was hypothesized that SP released from primary nociceptors could activate GABAergic interneurons in the DH of cat spinal cord (Wei and Zhao 1996). The increase of Fos expression in GABAergic neurons following intradermal capsaicin injection was observed in rat (Zou et al. 2001). Recently, Ferrini et al. (2007) detected increase of sIPSCs frequency induced by capsaicin administration $(2 \mu \mathrm{M})$ in lamina II neurons in spinal cord slice from mice pups (P8-P12). About $75 \%$ of sIPSCs were GABAergic and $25 \%$ were both GABA- and glycinergic. Capsaicin induced increase of sIPSCs frequency was attenuated by pretreatment with SB366791, a competitive highly selective antagonist of TRPV1. Effect of capsaicin on sIPSCs in lamina II neurons was substantially dependent on activation of NK1 receptors and largely blocked by tetrodotoxin application, suggesting an action potential mediated mechanism. The authors propose TRPV1 dependent release of SP which excites inhibitory neurons in laminae I, III and IV resulting in increased release of 
GABA and glycine in the area of lamina II. Increase of glycinergic sIPSCs in superficial dorsal horn induced by capsaicin administration in rat spinal cord slice was reported also by Zhou et al. (2008) in about $70 \%$ of lamina II neurons.

Direct functional connection between capsaicin sensitive fibers and NK1-expressing spinal cord neurons was indicated by Labrakakis and Mac Dermott (2003). Using fluorescence conjugated SP they labeled NK1 receptor-expressing neurons which are prominent in lamina I and sporadic in lamina III and IV. Labeled neurons were patch clamped and the increase of mEPSCs frequency was observed in about $73 \%$ of lamina I and $43 \%$ of lamina III/IV neurons expressing NK1 receptor following capsaicin administration. Using spinal cord slices from rats (P12-P25) labeled by voltage sensitive dye it was shown that capsaicin administration and increase in bath temperature inhibited excitation evoked by C-fibers intensity stimulation. This effect was abolished by TRPV1 antagonist capsazepine and by suramin, a purinoreceptor $\mathrm{P}_{2} \mathrm{X}$ and $\mathrm{P}_{2} \mathrm{Y}$ antagonist, but was facilitated by $P_{2} Y$ agonist (Kusudo et al. 2006).

\section{The role of spinal TRPV1 in pathological pain states}

Intrathecal injection of capsaicin leads to transient hyperalgesia that can switch to long-term analgesia. Thermal antinociception following intrathecal injection of capsaicin which correlated witch SP depletion in the rat and mice $\mathrm{DH}$ was demonstrated using hot-plate and tail-flick tests (Yaksh et al. 1979, Gamse 1982). Capsaicin injected intrathecally produced acute nocifensive behavior in mice, quantified as number of biting and scratching behavior. This response to capsaicin application was greatly reduced by intrathecal capsaicin or $\mathrm{SP}_{2} \mathrm{NH}_{2}$-terminal fragment (SP1-7) administration $24 \mathrm{~h}$ before (Mousseau et al. 1994). Acute nocifensive behavior following intrathecal capsaicin application was present in rats as early as postnatal day $10(\mathrm{P} 10)$ but was of longer duration in adult animals, while the intensity of the pain related behavior was the same in both age groups (Guo et al. 2001). Intrathecal application of TRPV1 agonist resiniferatoxin (RTX) led to ablation of TRPV1 expressing DRG neurons and to significant relief of hyperalgesia induced by inflammation in rats and arthritic pain in dogs (Karai et al. 2004).

Direct intrathecal application of TRPV1 antagonists displays antinociceptive effect in chronic pain states. Kanai et al. (2005) showed that intrathecal $\mathrm{N}$-(4-tertiarybutylphenyl)-4-(3-cholorphyridin-2-

yl)tetrahydro-pryazine-1(2H)-carbox-amide (BCTC), a selective antagonist of TRPV1 receptors, reduced mechanical allodynia present in model of chronic constriction injury. BCTC blocked also capsaicin stimulated release of neuropeptides in acute spinal cord slices. The analgesic effect of TRPV1 antagonist in the model of neuropathic pain could be partially mediated by up-regulation of TRPV1 receptors in the spinal cord as was documented by western blot analysis. Other recently developed TRPV1 receptors antagonists, A-784168 and A-795614, reduced inflammatory thermal hyperalgesia, mechanical allodynia and osteoarthritic pain following intrathecal administration (Cui et al. 2006).

Wilson-Gerwing et al. (2005) demonstrated that intrathecal infusion of nurotrophin-3 (NT-3), a negative modulator of nerve growth factor (NGF) expression, prevented or abolished the development of thermal hyperalgesia, but not mechanical hypersensitivity in the model of chronic constriction injury in rat. Thermal hyperalgesia in this experiment correlated with increased expression of TRPV1 mRNA and protein in DRG neurons. Thermal hypersensitivity and up-regulation of TRPV1 expression was reversed by infusion of NT-3. Increased TRPV1 expression was shown in the spinal cord dorsal horn of rats that had thermal hyperalgesia after spinal cord injury when compared to those without hyperalgesia (DomBourian et al. 2006). Carrageenan induced peripheral inflammation increased transport of TRPV1 mRNA from the cell body of DRG neurons to their dorsal horn terminals as was demonstrated by Tohda et al. (2001). The change in TRPV1 mRNA distribution was blocked by inhibitor of axonal transport colchicine. Capsaicin stimulated increased glutamate release in the dorsal horn during peripheral inflammation was abolished by cyclohexamide, an inhibitor of RNA translation and also by intrathecal injection of antisense oligonucleotides against TRPV1. The later method was also effective in reducing mechanical hypersensitivity in rats with spinal nerve ligation (Christoph et al. 2007).

Anandamide, an endogenous cannabinoid (CB) receptor and TRPV1 agonist, at high concentration can excite TRPV1-positive afferents in the dorsal horn leading to depletion of neuropeptides, while low concentration of anandamide gate the $\mathrm{CB}$ receptors linked to dorsal horn inhibition (Tognetto et al. 2001). Carrageenan induced thermal hyperalgesia (with acute transient pain behavior) was shown to be reduced by 
intrathecal administration of anandamide, while this effect was modulated by capsazepine (Horvath et al. 2008). However, the highest dose of anandamide $(100 \mu \mathrm{g})$ induced nocifensive behavior.

Lappin et al. (2006) demonstrated decrease of sEPSCs or mEPSCs frequency and reduction of amplitude of EPSCs evoked by C-fibers electric stimulation by bath administration of SB-366791 in dorsal horn neurons recorded in spinal cord slices from rats (P17-P29) after peripheral inflammation, while there was no effect of the antagonist in neurons recorded in slices from control animals. Based on these results authors suggest, that TRPV1 receptors in spinal cord DH become tonically active in animals with peripheral inflammation and enhance glutamate release. This is in good correspondence with findings, that capsaicin can induce higher concentration glutamate release from laminae I, II and X spinal cord located ipsilaterally to peripheral inflammation (Sasaki et al. 1998).

\section{Conclusions}

There is now mounting evidence suggesting that TRPV1 receptors present in the spinal cord dorsal horn play an important modulatory role in nociceptive and pain transmission. It needs to be further determined to what extent this role is important under control conditions and in different chronic pain states. Spinal cord TRPV1 receptors may represent an attractive target for pain therapy in the future.

\section{Conflict of Interest}

There is no conflict of interest.

\section{Acknowledgements}

Supported by GACR 305/06/1115, GACR 304/08/0256, MSMT CR LC554, MYORES LSH-CT-2004-511978, AV0Z 50110509.

\section{References}

ACS G, BLUMBERG PM: Comparison of $\left[{ }^{3} \mathrm{H}\right]$ resiniferatoxin binding to spinal cord and dorsal root ganglia of newborn and adult rats. Life Sci 54: 1875-1882, 1994.

ACS G, PALKOVITS M, BLUMBERG PM: Comparison of $\left[{ }^{3} \mathrm{H}\right]$ resiniferatoxin binding by the vanilloid (capsaicin) receptor in dorsal root ganglia, spinal cord, dorsal vagal complex, sciatic and vagal nerve and urinary bladder of the rat. Life Sci 55: 1017-1026, 1994.

BACCEI ML, BARDONI R, FITZGERALD M: Development of nociceptive synaptic inputs to the neonatal rat dorsal horn: glutamate release by capsaicin and menthol. J Physiol Lond 549: 231-242, 2003.

CATERINA MJ, LEFFLER A, MALMBERG AB, MARTIN WJ, TRAFTON J, PETERSEN-ZEITZ KR, KOLTZENBURG M, BASBAUM AI, JULIUS D: Impaired nociception and pain sensation in mice lacking the capsaicin receptor. Science 288: 306-313, 2000.

CATERINA MJ, SCHUMACHER MA, TOMINAGA M, ROSEN TA, LEVINE JD, JULIUS D: The capsaicin receptor: a heat-activated ion channel in the pain pathway. Nature 389: 816-824, 1997.

CORTRIGHT DN, SZALLASI A: Biochemical pharmacology of the vanilloid receptor TRPV1. An update. Eur $J$ Biochem 271: 1814-1819, 2004.

CUI M, HONORE P, ZHONG C, GAUVIN D, MIKUSA J, HERNANDEZ G, CHANDRAN P, GOMTSYAN A, BROWN B, BAYBURT EK, MARSH K, BIANCHI B, MCDONALD H, NIFORATOS W, NEELANDS TR, MORELAND RB, DECKER MW, LEE CH, SULLIVAN JP, FALTYNEK CR: TRPV1 receptors in the CNS play a key role in broad-spectrum analgesia of TRPV1 antagonists. J Neurosci 26: 9385-9393, 2006.

DAVIS JB, GRAY J, GUNTHORPE MJ, HATCHER JP, DAVEY PT, OVEREND P, HARRIES MH, LATCHAM J, CLAPHAM C, ATKINSON K, HUGHES SA, RANCE K, GRAU E, HARPER AJ, PUGH PL, ROGERS DC, BINGHAM S, RANDALL A, SHEARDOWN SA: Vanilloid receptor-1 is essential for inflammatory thermal hyperalgesia. Nature 405: 183-187, 2000.

DOLY S, FISCHER J, CONRATH M: The vanilloid receptor-1 (TRPV1) is expressed in some rat dorsal horn NK1 cells. Brain Res 1004: 203-207, 2004a.

DOLY S, FISCHER J, SALIO C, CONRATH M: The vanilloid receptor-1 is expressed in rat spinal dorsal horn astrocytes. Neurosci Lett 357: 123-126, 2004 b. 
DOMBOURIAN MG, TURNER NA, GEROVAC TA, VEMUGANTI R, MIRANPURI GS, TUREYEN K, SATRIOTOMO I, MILETIC V, RESNICK DK: B1 and TRPV-1 receptor genes and their relationship to hyperalgesia following spinal cord injury. Spine 31: 2778-2782, 2006.

FERRINI F, SALIO C, VERGNANO AM, MERIGHI A: Vanilloid receptor-1 (TRPV1)-dependent activation of inhibitory neurotransmission in spinal substantia gelatinosa neurons of mouse. Pain 129: 195-209, 2007.

GAMSE R: Capsaicin and nociception in the rat and mouse. Possible role of substance P. Naunyn-Schmiedebergs Arch Pharmacol 320: 205-216, 1982.

GUO A, SIMONE DA, STONE LS, FAIRBANKS CA, WANG J, ELDE R: Developmental shift of vanilloid receptor 1 (VR1) terminals into deeper regions of the superficial dorsal horn: correlation with a shift from TrkA to Ret expression by dorsal root ganglion neurons. Eur J Neurosci 14: 293-304, 2001.

GUO A, VULCHANOVA L, WANG J, LI X, ELDE R: Immunocytochemical localization of the vanilloid receptor 1 (VR1): relationship to neuropeptides, the P2X3 purinoceptor and IB4 binding sites. Eur J Neurosci 11: 946958, 1999.

HORVATH G, KEKESI G, NAGY E, BENEDEK G: The role of TRPV1 receptors in the antinociceptive effect of anandamide at spinal level. Pain 134: 277-284, 2008.

HUANG SM, BISOGNO T, TREVISANI M, AL-HAYANI A, DE PETROCELliS L, FEZZA F, TOGNETTO M, PETROS TJ, KREY JF, CHU CJ, MILLER JD, DAVIES SN, GEPPETTI P, WALKER JM, DI MARZO V: An endogenous capsaicin-like substance with high potency at recombinant and native vanilloid VR1 receptors. Proc Natl Acad Sci USA 99: 8400-8405, 2002.

HWANG SJ, BURETTE A, RUSTIONI A, VALTSCHANOFF JG: Vanilloid receptor VR1-positive primary afferents are glutamatergic and contact spinal neurons that co-express neurokinin receptor NK1 and glutamate receptors. J Neurocytol 33: 321-329, 2004.

HWANG SJ, BURETTE A, VALTSCHANOFF JG: VR1-positive primary afferents contact NK1-positive spinoparabrachial neurons. J Comp Neurol 460: 255-265, 2003.

HWANG SJ, VALTSCHANOFF JG: Vanilloid receptor VR1-positive afferents are distributed differently at different levels of the rat lumbar spinal cord. Neurosci Lett 349: 41-44, 2003.

HWANG SW, CHO H, KWAK J, LEE SY, KANG CJ, JUNG J, CHO S, MIN KH, SUH YG, KIM D, OH U: Direct activation of capsaicin receptors by products of lipoxygenases: endogenous capsaicin-like substances. Proc Natl Acad Sci USA 97: 6155-6160, 2000.

CHRISTOPH T, GILLEN C, MIKA J, GRUNWELLER A, SCHAFER MK, SCHIENE K, FRANK R, JOSTOCK R, BAHRENBERG G, WEIHE E, ERDMANN VA, KURRECK J: Antinociceptive effect of antisense oligonucleotides against the vanilloid receptor VR1/TRPV1. Neurochem Int 50: 281-290, 2007.

CHU CJ, HUANG SM, DE PETROCELLIS L, BISOGNO T, EWING SA, MILLER JD, ZIPKIN RE, DADDARIO N, APPENDINO G, DI MARZO V, WALKER JM: N-oleoyldopamine, a novel endogenous capsaicin-like lipid that produces hyperalgesia. $J$ Biol Chem 278: 13633-13639, 2003.

JANCSO G, KIRALY E, JANCSO-GABOR A: Pharmacologically induced selective degeneration of chemosensitive primary sensory neurones. Nature 270: 741-743, 1977.

JANCSO G, KIRALY E, SUCH G, JOO F, NAGY A: Neurotoxic effect of capsaicin in mammals. Acta Physiol Hung 69: 295-313, 1987.

JHAMANDAS K, YAKSH TL, HARTY G, SZOLCSANYI J, GO VL: Action of intrathecal capsaicin and its structural analogues on the content and release of spinal substance P: selectivity of action and relationship to analgesia. Brain Res 306: 215-225, 1984.

JI RR, SAMAD TA, JIN SX, SCHMOLL R, WOOLF CJ: p38 MAPK activation by NGF in primary sensory neurons after inflammation increases TRPV1 levels and maintains heat hyperalgesia. Neuron 36: 57-68, 2002.

KANAI Y, NAKAZATO E, FUJIUCHI A, HARA T, IMAI A: Involvement of an increased spinal TRPV1 sensitization through its up-regulation in mechanical allodynia of CCI rats. Neuropharmacology 49: 977-984, 2005.

KANGRGA I, RANDIC M: Tachykinins and calcitonin gene-related peptide enhance release of endogenous glutamate and aspartate from the rat spinal dorsal horn slice. J Neurosci 10: 2026-2038, 1990. 
KARAI L, BROWN DC, MANNES AJ, CONNELLY ST, BROWN J, GANDAL M, WELLISCH OM, NEUBERT JK, OLAH Z, IADAROLA MJ: Deletion of vanilloid receptor 1-expressing primary afferent neurons for pain control. J Clin Invest 113: 1344-1352, 2004.

KNOTKOVA H, PAPPAGALLO M, SZALLASI A: Capsaicin (TRPV1 agonist) therapy for pain relief: farewell or revival? Clin J Pain 24: 142-154, 2008.

KUSUDO K, IKEDA H, MURASE K: Depression of presynaptic excitation by the activation of vanilloid receptor 1 in the rat spinal dorsal horn revealed by optical imaging. Mol Pain 2: 8, 2006.

LABRAKAKIS C, MACDERMOTT AB: Neurokinin receptor 1-expressing spinal cord neurons in lamina I and III/IV of postnatal rats receive inputs from capsaicin sensitive fibers. Neurosci Lett 352: 121-124, 2003.

LAPPIN SC, RANDALL AD, GUNTHORPE MJ, MORISSET V: TRPV1 antagonist, SB-366791, inhibits glutamatergic synaptic transmission in rat spinal dorsal horn following peripheral inflammation. Eur $J$ Pharmacol 540: 73-81, 2006.

MANTYH PW, ROGERS SD, HONORE P, ALLEN BJ, GHILARDI JR, LI J, DAUGHTERS RS, LAPPI DA, WILEY RG, SIMONE DA: Inhibition of hyperalgesia by ablation of lamina I spinal neurons expressing the substance P receptor. Science 278: 275-279, 1997.

MATTA JA, MIYARES RL, AHERN GP: TRPV1 is a novel target for omega-3 polyunsaturated fatty acids. $J$ Physiol Lond 578: 397-411, 2007.

MICEVYCH PE, YAKSH TL, SZOLCSANYI J: Effect of intrathecal capsaicin analogues on the immunofluorescence of peptides and serotonin in the dorsal horn in rats. Neuroscience 8: 123-131, 1983.

MOUSSEAU DD, SUN X, LARSON AA: An antinociceptive effect of capsaicin in the adult mouse mediated by the $\mathrm{NH}_{2}$-terminus of substance P. J Pharmacol Exp Ther 268: 785-790, 1994.

NAGY JI, IVERSEN LL, GOEDERT M, CHAPMAN D, HUNT SP: Dose-dependent effects of capsaicin on primary sensory neurons in the neonatal rat. J Neurosci 3: 399-406, 1983.

NUMAZAKI M, TOMINAGA M: Nociception and TRP channels. Curr Drug Targets CNS Neurol Disord 3: 479-485, 2004.

POSPISILOVÁ E, PALECEK J: Post-operative pain behavior in rats is reduced after single high-concentration capsaicin application. Pain 125: 233-243, 2006.

SARIA A, GAMSE R, PETERMANN J, FISCHER JA, THEODORSSON-NORHEIM E, LUNDBERG JM: Simultaneous release of several tachykinins and calcitonin gene-related peptide from rat spinal cord slices. Neurosci Lett 63: 310-314, 1986.

SASAKI M, TOHDA C, KURAISHI Y: Region-specific increase in glutamate release from dorsal horn of rats with adjuvant inflammation. Neuroreport 9: 3219-3222, 1998.

SIMONE DA, BAUMANN TK, LAMOTTE RH: Dose-dependent pain and mechanical hyperalgesia in humans after intradermal injection of capsaicin. Pain 38: 99-107, 1989.

SIMONE DA, NOLANO M, JOHNSON T, WENDELSCHAFER-CRABB G, KENNEDY WR: Intradermal injection of capsaicin in humans produces degeneration and subsequent reinnervation of epidermal nerve fibers: correlation with sensory function. J Neurosci 18: 8947-8959, 1998.

SIMONE DA, SORKIN LS, OH U, CHUNG JM, OWENS C, LAMOTTE RH, WILLIS WD: Neurogenic hyperalgesia: central neural correlates in responses of spinothalamic tract neurons. J Neurophysiol 66: 228-246, 1991.

STAROWICZ K, NIGAM S, Di MARZO V: Biochemistry and pharmacology of endovanilloids. Pharmacol Ther 114: 13-33, 2007.

SZALLASI A, BLUMBERG PM, NILSSON S, HOKFELT T, LUNDBERG JM: Visualization by $\left[{ }^{3} \mathrm{H}\right]$ resiniferatoxin autoradiography of capsaicin-sensitive neurons in the rat, pig and man. Eur J Pharmacol 264: 217-221, 1994.

SZALLASI A, CORTRIGHT DN, BLUM CA, EID SR: The vanilloid receptor TRPV1: 10 years from channel cloning to antagonist proof-of-concept. Nat Rev Drug Discov 6: 357-372, 2007.

SZALLASI A, NILSSON S, FARKAS-SZALLASI T, BLUMBERG PM, HOKFELT T, LUNDBERG JM: Vanilloid (capsaicin) receptors in the rat: distribution in the brain, regional differences in the spinal cord, axonal transport to the periphery, and depletion by systemic vanilloid treatment. Brain Res 703: 175-183, 1995.

TODD AJ: Anatomy of primary afferents and projection neurones in the rat spinal dorsal horn with particular emphasis on substance P and the neurokinin 1 receptor. Exp Physiol 87: 245-249, 2002. 
TOGNETTO M, AMADESI S, HARRISON S, CREMINON C, TREVISANI M, CARRERAS M, MATERA M, GEPPETTI P, BIANCHI A: Anandamide excites central terminals of dorsal root ganglion neurons via vanilloid receptor-1 activation. J Neurosci 21: 1104-1109, 2001.

TOHDA C, SASAKI M, KONEMURA T, SASAMURA T, ITOH M, KURAISHI Y: Axonal transport of VR1 capsaicin receptor mRNA in primary afferents and its participation in inflammation-induced increase in capsaicin sensitivity. J Neurochem 76: 1628-1635, 2001.

TOMINAGA M, CATERINA MJ, MALMBERG AB, ROSEN TA, GILBERT H, SKINNER K, RAUMANN BE, BASBAUM AI, JULIUS D: The cloned capsaicin receptor integrates multiple pain-producing stimuli. Neuron 21: 531-543, 1998.

UEDA M, KURAISHI Y, SUGIMOTO K, SATOH M: Evidence that glutamate is released from capsaicin-sensitive primary afferent fibers in rats: study with on-line continuous monitoring of glutamate. Neurosci Res 20: 231237, 1994.

VALTSCHANOFF JG, RUSTIONI A, GUO A, HWANG SJ: Vanilloid receptor VR1 is both presynaptic and postsynaptic in the superficial laminae of the rat dorsal horn. J Comp Neurol 436: 225-235, 2001.

VENKATACHALAM K, MONTELL C: TRP channels. Annu Rev Biochem 76: 387-417, 2007.

VENNEKENS R, OWSIANIK G, NILIUS B: Vanilloid transient receptor potential cation channels: an overview. Curr Pharm Des 14: 18-31, 2008.

WEI F, ZHAO ZQ: Blockade of capsaicin-induced reduction of GABA-immunoreactivity by spantide in cat spinal superficial dorsal horn. Neuroscience 71: 277-283, 1996.

WILLIS WD: Role of neurotransmitters in sensitization of pain responses. Ann N Y Acad Sci 933: 142-156, 2001.

WILSON-GERWING TD, DMYTERKO MV, ZOCHODNE DW, JOHNSTON JM, VERGE VM: Neurotrophin-3 suppresses thermal hyperalgesia associated with neuropathic pain and attenuates transient receptor potential vanilloid receptor-1 expression in adult sensory neurons. J Neurosci 25: 758-767, 2005.

YAKSH TL, FARB DH, LEEMAN SE, JESSELL TM: Intrathecal capsaicin depletes substance P in the rat spinal cord and produces prolonged thermal analgesia. Science 206: 481-483, 1979.

YANG K, KUMAMOTO E, FURUE H, LI YQ, YOSHIMURA M: Action of capsaicin on dorsal root-evoked synaptic transmission to substantia gelatinosa neurons in adult rat spinal cord slices. Brain Res 830: 268-273, 1999.

YANG K, KUMAMOTO E, FURUE H, YOSHIMURA M: Capsaicin facilitates excitatory but not inhibitory synaptic transmission in substantia gelatinosa of the rat spinal cord. Neurosci Lett 255: 135-138, 1998.

ZHOU HY, ZHANG HM, CHEN SR, PAN HL: Increased C-fiber nociceptive input potentiates inhibitory glycinergic transmission in the spinal dorsal horn. J Pharmacol Exp Ther 324: 1000-1010, 2008.

ZOU X, LIN Q, WILLIS WD: NMDA or non-NMDA receptor antagonists attenuate increased Fos expression in spinal dorsal horn GABAergic neurons after intradermal injection of capsaicin in rats. Neuroscience 106: 171-182, 2001.

ZYGMUNT PM, PETERSSON J, ANDERSSON DA, CHUANG H, SORGARD M, Di MARZO V, JULIUS D, HOGESTATT ED: Vanilloid receptors on sensory nerves mediate the vasodilator action of anandamide. Nature 400: 452-457, 1999. 